\title{
Interaction of Platelet-Derived Microparticles with a Human B-Lymphoblast Cell Line: A Clue for the Immunologic Function of the Microparticles
}

\author{
Fatemah Yari Mahboubeh Motefaker Mahin Nikougoftar Zahra Khayati \\ Iranian Blood Transfusion Research Center, High Institute for Research and Education in Transfusion Medicine, Tehran, Iran
}

\section{Keywords}

Platelet microparticles · Daudi · CD27 · CD86 · lgG

\section{Summary}

Background: Platelets are blood cells with extensive capabilities in hemostasis. They also play a central role in the development of innate and adaptive immune responses. Little information exists about the immunostimulatory role of platelet-derived microparticles (PItMPs). To further elucidate this issue, we conducted this study using the B-lymphoblast cell line 'Daudi' as an available surrogate cell line for peripheral blood B lymphocytes. This cell line does not produce immunoglobulins (Igs) and has low expression of activation markers. Methods: Plt-MPs were isolated from platelet concentrate $(P C)$ using a multi-step centrifugation method. Daudi cells were treated with PIt-MPs in the culture medium while no treatment was given to the control cells. During 5-day co-culture, Daudi cells were evaluated for the $\mathrm{lg}$ production and the expression of the cell surface markers CD86, CD27, and IgD. Results: An increase was observed for the production of $\lg G$ and the expression of CD27 and CD86 on Daudi cells in response to Plt-MPs, whereas the $\lg D$ level was decreased. The response of Daudi cells was dependent on the concentration of PltMPs and the time of their isolation from PCs during storage. The differences of the variables were significant between the treatment and control groups. Conclusion: PltMPs could induce the activation and differentiation of immortalized cells of B-cell origin. Thus it is conceivable that PIt-MPs may play a significant role as immortalized cell activators in human monoclonal antibody technology in near future.

(C) 2017 S. Karger GmbH, Freiburg

\section{KARGER}

(C) 2017 S. Karger GmbH, Freiburg

\section{Introduction}

B lymphocytes recognize extracellular soluble and cell surface antigens and differentiate into antibody-secreting plasma cells. The response of $\mathrm{B}$ cells to protein antigens requires help from CD4+ helper T cells. CD40L on the surface of T cells is a type II membrane protein which mediates the activation, proliferation, and differentiation of B cells. Interestingly, platelets express CD40L which is an important molecule in motivating immune cells [1]. Many immunological activities of platelets are mediated by CD40L. In addition to innate immune responses, platelets play an important role in adaptive immunity $[1,2]$. Human platelets activate dendritic cells, increase T-cell response, induce the production of IgG antibodies from B cells, and increase the formation of germinal centers together with T cells [3].

Microparticles (MPs) are a heterogeneous population of spherical structures with a diameter of 100 to $1,000 \mathrm{~nm}$ that germinate from the plasma membrane of different cells. They express the specific antigens of the primary cells on their surface [4]. MPs in the blood are derived from several cells such as platelets, red blood cells, granulocytes, endothelial cells and cancer cells, with plateletderived MPs (Plt-MPs) being the most frequent $[5,6]$. Overexpression of MPs is associated with different physiological and pathophysiological conditions [7-9]. Plt-MPs, like their mother cells, express many antigens such as CD41, CD61, CD62P and CD40L. These MPs are also involved in hemostatic and inflammatory responses [10], vascular repair as well as angiogenesis [11]. Divergences in the number of Plt-MPs may be associated with a tendency to bleeding such as Scott syndrome [12]. Plt-MPs are involved in the movement of mRNA and small RNA (microRNA) [13], cellular communications [13], improving the stem cell transplant [14], bioactive lipids transfer [15], and immunomodulation due to the expression of CD40L $[1,3]$. Additionally, evidence was provided showing that Plt-MPs have the ability to transfer their surface receptors to other cells; so they may be involved in the 


\begin{tabular}{|c|c|c|c|c|c|}
\hline & & & Diam. (nm) & $\%$ Intensity & Width (nm) \\
\hline Z-Average (d.nm): & 782 & Peak 1: & 797 & 69.3 & 77.9 \\
\hline Pd: & 0.642 & Peak 2: & 146 & 30.7 & 14.1 \\
\hline Intercept: & 0.845 & Peak 3: & 0.00 & 0.0 & 0.00 \\
\hline
\end{tabular}

Fig. 1. The size distribution of platelet MPs. The distribution of light scattered by Plt-MPs was measured and analyzed to obtain the size distributions as the intensity (\%) versus diameter in $\mathrm{nm}$ (d.nm). Size less than $1,000 \mathrm{~nm}$ were in compliance with the predicted size range (between 100 to $1,000 \mathrm{~nm}$ ) for MPs.

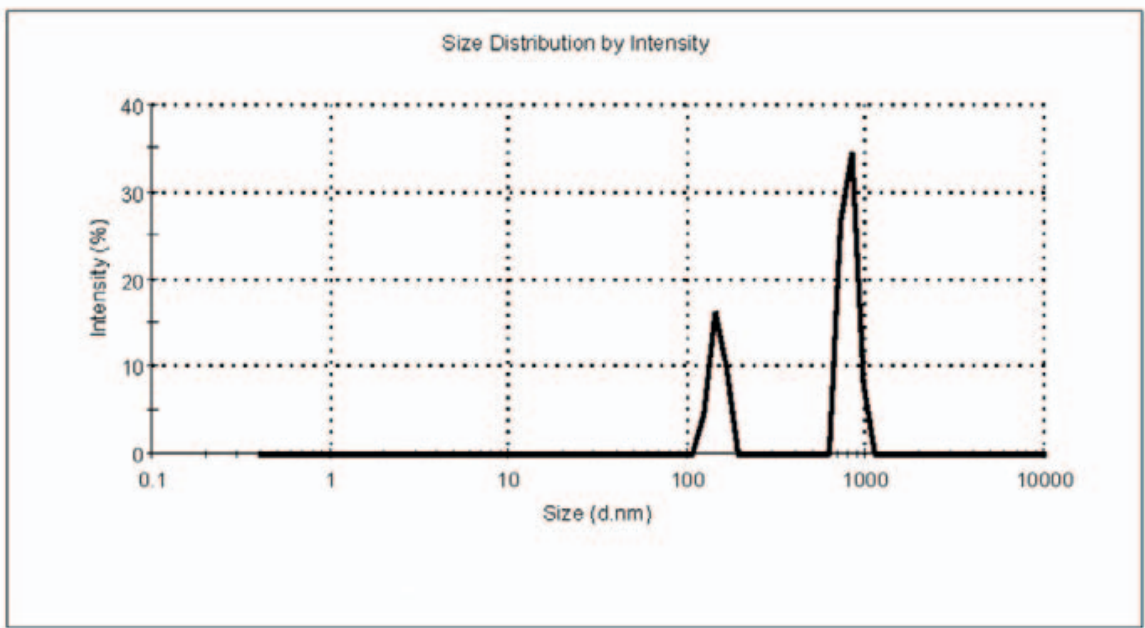

transfer of CXCR4 co-receptor and can increase the sensitivity of CD34+ cells to infection with HIV [16]. Plt-MPs can be obtained from platelet concentrates (PCs) during storage or even after the expiration date.

The impact of platelets on peripheral blood B cells has been previously mentioned $[1,17]$. But the studies dealing with this issue are very scarce. Here we intended to evaluate the ability of Plt-MPs to activate and initiate the differentiation of an immortalized B-cell line (Daudi) as a surrogate cell line for peripheral blood B lymphocytes. Because of naturally or experimentally induced mutation, an immortalized cell line can be grown for extended times in vitro. Daudi is a well characterized lymphoblastoid cell line and has been created by infection of B cells with Epstein-Barr virus (EBV) virus. Obtaining sufficient numbers of these cells through cell culture is easier than the isolation of peripheral blood B lymphocytes from human whole blood. The results of this study may be useful for studies related to human monoclonal antibody production via EBV-transformed human B-cell lines.

\section{Material and Methods}

\section{Preparation of PCs}

After obtaining informed consent, whole blood was collected from blood donors by the Iranian Blood Transfusion Organization (IBTO) [18]. Five single-donor PC bags (JMS Singapore Pte Ltd., Singapore) were prepared. The bags were kept on a platelet shaker incubator at $22-24^{\circ} \mathrm{C}$ for 7 days [19]. Sampling was carried out at the $3 \mathrm{rd}$ and 7 th days of the storage period. PC samples were used for Plt-MP preparation.

Isolation and Characterization of Plt-MPs

The cell content of the PC was removed by centrifugation at $1,200 \times g$ for 12 $\min$ [20]. The plasma portion of the PC was then centrifuged at $15,800 \times g$ for 15 min for the isolation of Plt-MPs [20]. The Plt-MPs were obtained and
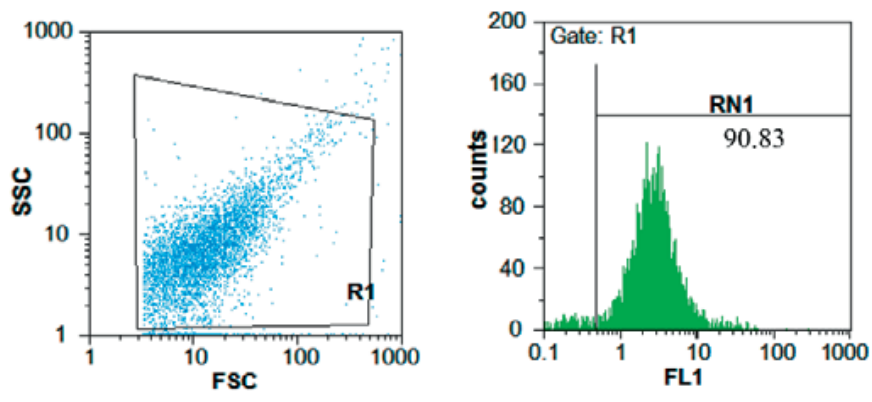

A

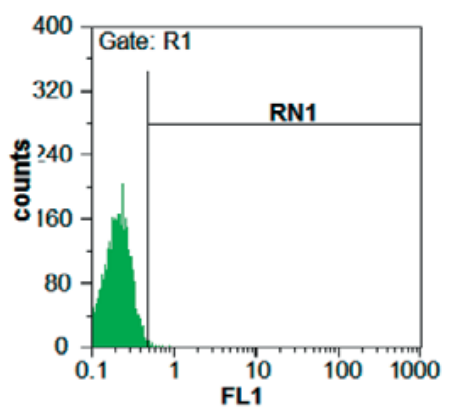

C

Fig. 2. Flow cytometry plot. The expression of $C D 41$ on platelet MPs was determined using FITC-conjugated anti-CD41. (A) Gating of MPs (B) The level CD41 expression on MPs $(\mathbf{C})$ isotype control. The results demonstrated that the CD41 antigen is highly expressed on MPs and they have platelet origin.

washed 2 times with PBS and their protein concentration was determined using the Bradford method. Subsequently we used a particle-sizing instrument, Malvern Mastersizer 2000 laser diffraction system (Malvern Instruments Ltd, Worcestershire, UK), to measure the distribution of light scattered from the 


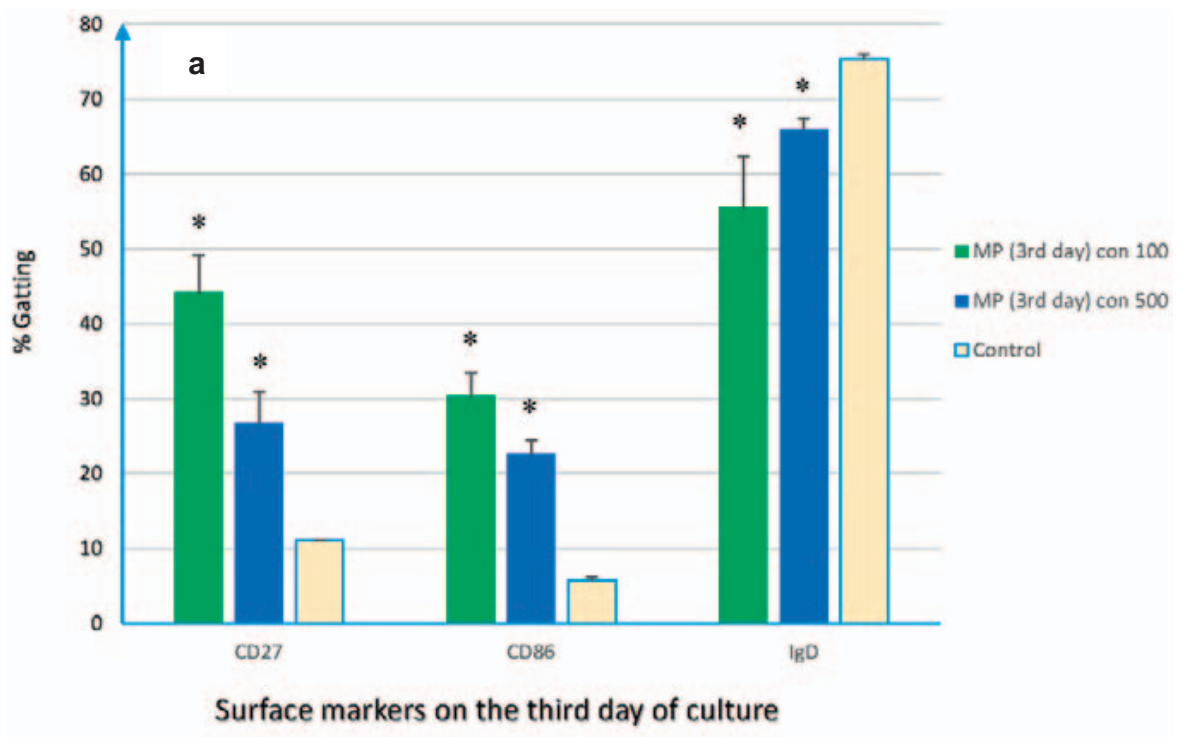

Fig. 3. Flow cytometry results. Plt-MPs were isolated from platelet concentrate at the 3rd day of storage. Daudi cells were treated with different concentrations of the isolated Plt-MPs for 5 days. After the co-culture time, the expression of CD86, $\mathrm{CD} 27$ and IgD molecules was compared between the test (Daudi + Plt-MPs 3rd day) and control (Daudi) cells. The increasing profile for CD86, $\mathrm{CD} 27$ and decreasing profile for $\mathrm{IgD}$ were seen on Daudi cells at the 3rd (a) and 5th (b) days of coculture. Data were presented as the mean \pm SD of five experiments. ${ }^{*}$ Indicates the significant difference between the test and control $(\mathrm{p}<0.05)$.

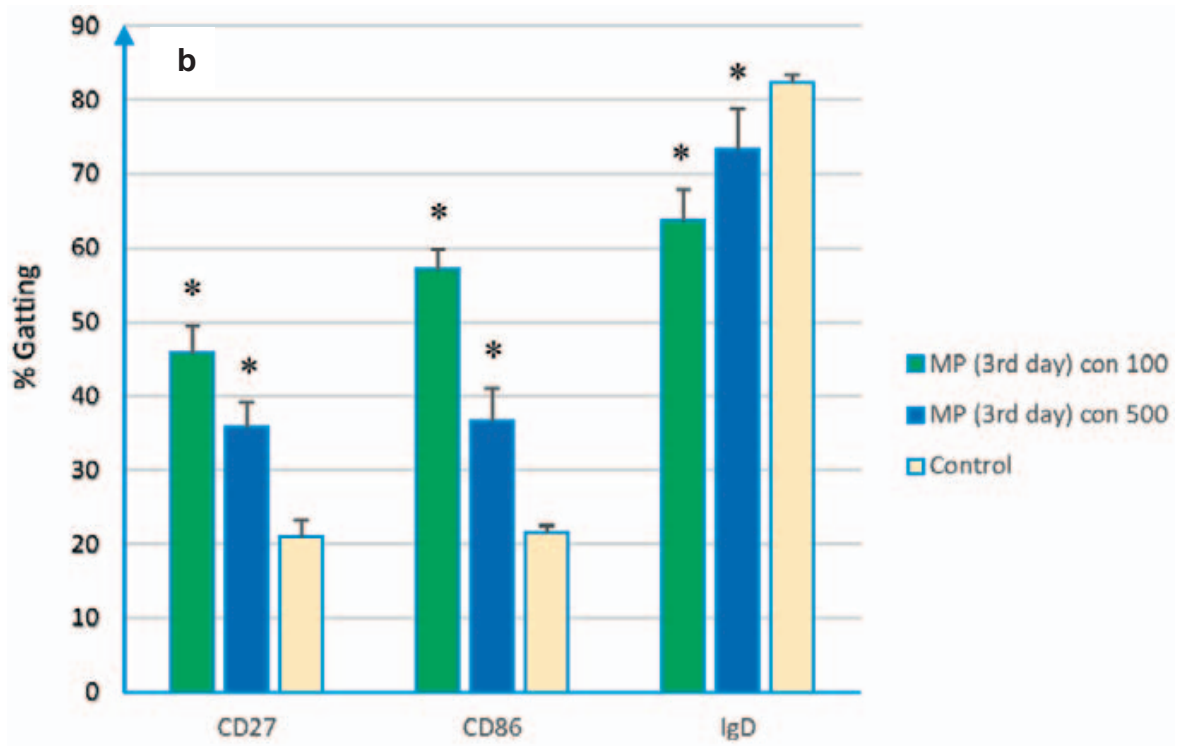

\section{Surface markers on the fifth day of culture}

sample illuminated by a laser. The size distribution was calculated using the software supplied with the instrument. Then, the specificity of MPs was surveyed by the evaluation of CD41 expression using FITC-conjugated anti-CD41 (clone number HIP8; Abbiotec LCC, San Diego, CA, USA). $5 \mu \mathrm{l}$ of the conjugate was added to the tubes contained $100 \mu \mathrm{l}$ of $100 \mu \mathrm{g} / \mathrm{ml}$ Plt-MPs. The tubes were left for $35 \mathrm{~min}$ at room temperature. Washing of the Plt-MPs was then carried out, and the analysis was done by flow cytometry using the CyFlow ${ }^{\circledR}$ Space (Sysmex, Norderstedt, Germany). For all experiments, the nonspecific antibody background binding was determined using the FITC-labeled mouse IgG1 isotype control.

\section{Co-Culture of Daudi Cells and Plt-MPs}

Daudi cells were cultured and exposed with Plt-MPs in the RPMI culture medium supplemented with $10 \%$ fetal bovine serum, $10,000 \mathrm{IU} / \mathrm{ml}$ penicillin, $10,000 \mathrm{ug} / \mathrm{ml}$ streptomycin, and $2 \mathrm{mmol} / \mathrm{l} \mathrm{L}$-glutamine and incubated at $37{ }^{\circ} \mathrm{C}$ and $5 \% \mathrm{CO}_{2}$ for 5 days. MPs were used at the concentrations of $100 \mu \mathrm{g} / \mathrm{ml}$ and $500 \mu \mathrm{g} / \mathrm{ml}$. Control samples were composed as described above without addition of MPs. Sampling of the cells was carried out at the 3rd and 5th days of co-culture.
The Immunophenotyping of Daudi Cells after Treatment with Plt-MPs

The expression of CD27, CD86, and IgD was measured on Daudi cells during 5-day exposure to Plt-MPs using flow cytometry technique. $3 \mu \mathrm{l}$ of mouse anti-human CD27 (clone number LT27; Abcam, Cambridge, UK) and CD86 (clone number B72-H2; Abcam) were separately added to tubes containing 100 $\mu \mathrm{l}\left(10^{5}\right.$ cells $)$ of a Daudi cell solution $\left(10^{6}\right.$ cells $\left./ \mathrm{ml}\right)$. The tubes were left for 35 $\min$ at $4{ }^{\circ} \mathrm{C}$. Washing of the cells was then carried out, and the second antibody (FITC-conjugated anti-mouse IgG, F(ab) ' ${ }_{2}$ (Dako, Bollschweil, Germany)) was then added. Analysis was accomplished by flow cytometry. In addition, for IgD measurement in a one-step method $5 \mu \mathrm{l}$ of FITC-conjugated goat anti-human $\operatorname{IgD}$ ( $\delta$-chain-specific) (Sigma Aldrich, St. Louis, MO, USA) was added to the cells. Analysis was carried out by flow cytometry after 35 min incubation at $4{ }^{\circ} \mathrm{C}$. In all experiments, nonspecific antibody background binding was determined using a FITC-labeled isotype control.

\section{Measurement of IgG Immunoglobulin Levels}

Total IgG was quantified in the supernatant of the culture medium by a sandwich ELISA method using human IgG ELISA kit (Abcam). After highspeed centrifugation and removal of the the cells and Plt-MPs, the test samples were added to the wells of an anti-human IgG-coated ELISA plate. After one 


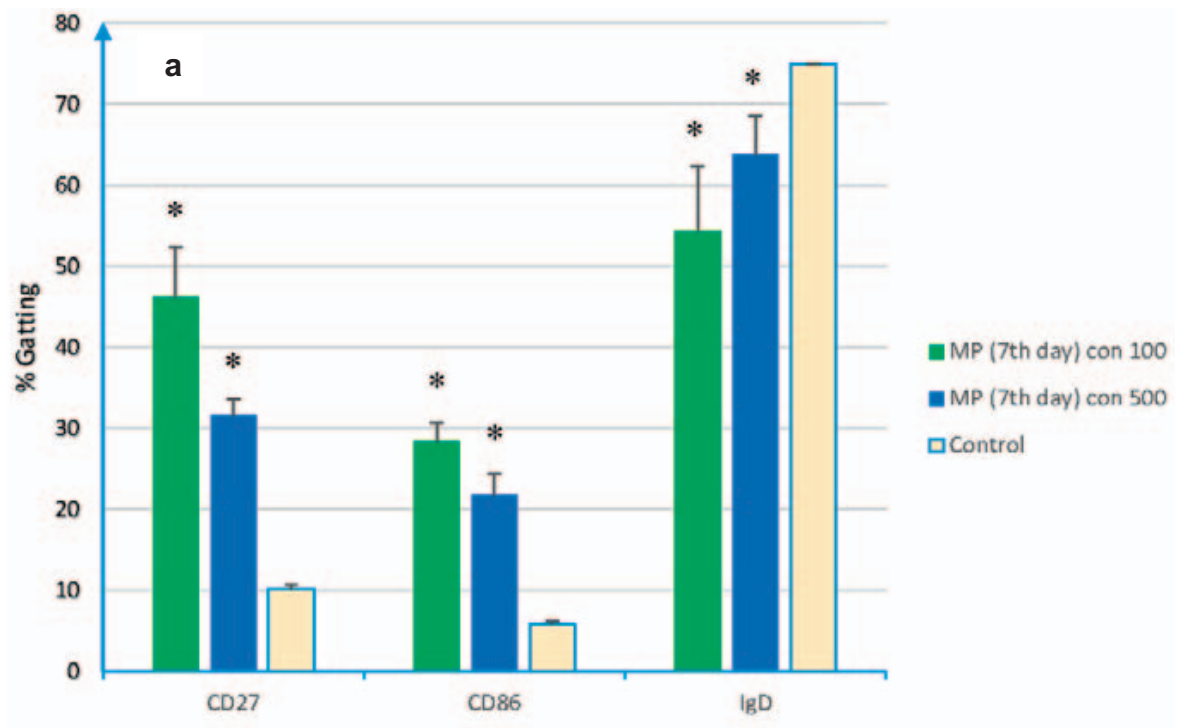

Surface markers on the third day of culture

Fig. 4. Flow cytometry results. Plt-MPs were isolated from platelet concentrate at the 7th day of storage. Daudi cells were treated with different concentrations of the isolated Plt-MPs for 5 days. After the co-culture time, the expression of CD86, CD27 and IgD was compared between the test (Daudi+ Plt-MPs 7th day) and control (Daudi) cells. The increasing profile for CD86, CD27 and decreasing profile for $\operatorname{IgD}$ were seen on the Daudi cells at the 3 rd (a) and 5 th $(\mathbf{b})$ days of co-culture. Data were presented as the mean \pm SD of five experiments. ${ }^{*}$ Indicates the significant difference between the test and control $(\mathrm{p}<0.05)$.

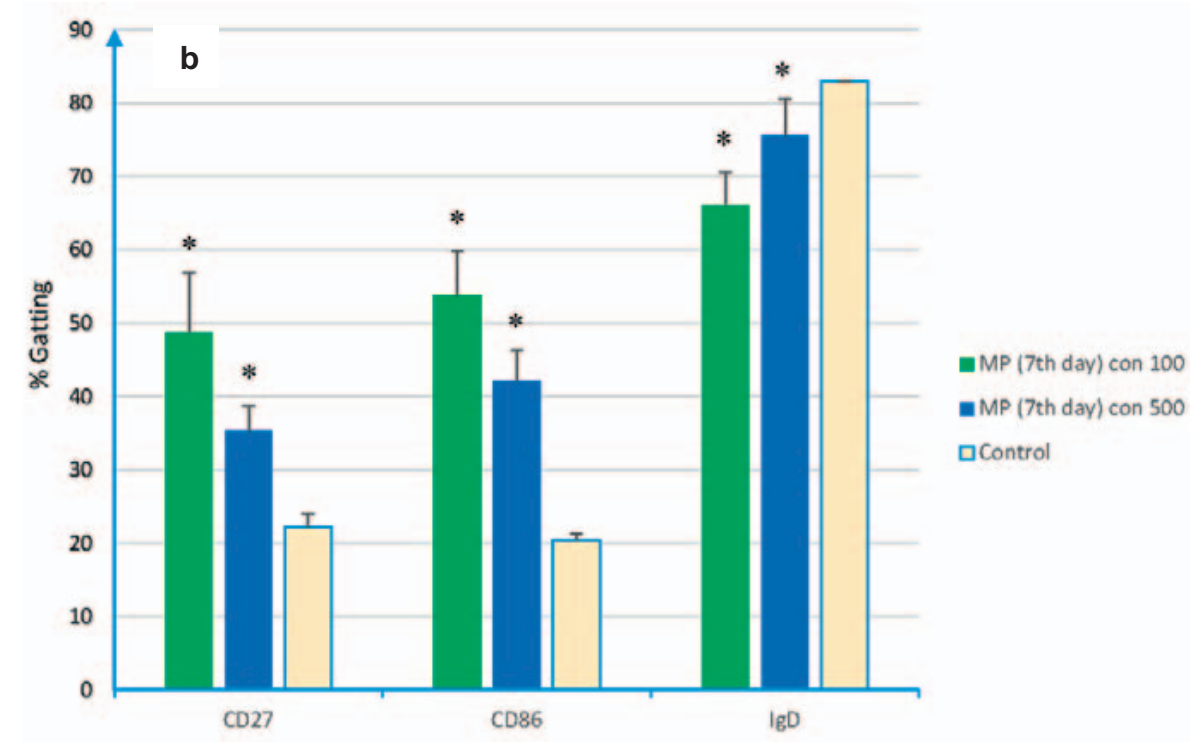

Surface markers on the fifth day of culture washing step, biotin-conjugated anti-human IgG was added to the wells as detection antibody. Then, streptavidin-conjugated horseradish peroxidase was used. After the incubation and washing steps, TMB substrate solution was used to determine the enzyme activity. Sulfuric acid was subsequently used to stop the enzyme reaction. Finally, the optical density was read at $450 \mathrm{~nm}$, and a standard curve was plotted to obtain the IgG levels.

\section{Statistical Analysis}

A non-parametric statistical test (Wilcoxon) was used to compare the results of this experiment. A p value $<0.05$ was considered statistically significant.

\section{Results}

\section{Characterization of Plt-MPs}

The size of the isolated MPs ranges between 100 and 1,000 nm $(\mathrm{Z}$-average $=782 \mathrm{~nm})$. A typical graph of intensity percentage ver- sus diameter was shown in figure 1 . The platelet origin of the isolated MPs was demonstrated by flow cytometry using an FITCconjugated anti-CD41 monoclonal antibody. High-level expression of CD41 was shown on the MPs (87 $\pm 4 \%$ ) (fig. 2).

The Immunophenotyping Results of Daudi Cells after Treatment with Plt-MPs

Changes in B-cell surface markers were examined on Daudi cells. Using flow cytometry, it became clear that the levels of CD86 and CD27 were significantly increased, whereas the IgD level was decreased on the Daudi cell line during 5-day co-culture with MPs. Detailed results of the expression levels of the markers on Daudi cells were given in figures 3 and 4 . It should be noted that Plt-MPs were achieved from PCs at the $3 \mathrm{rd}$ and 7 th days of storage and used at two different concentrations (100 and $500 \mu \mathrm{g} / \mathrm{ml}$ ). 


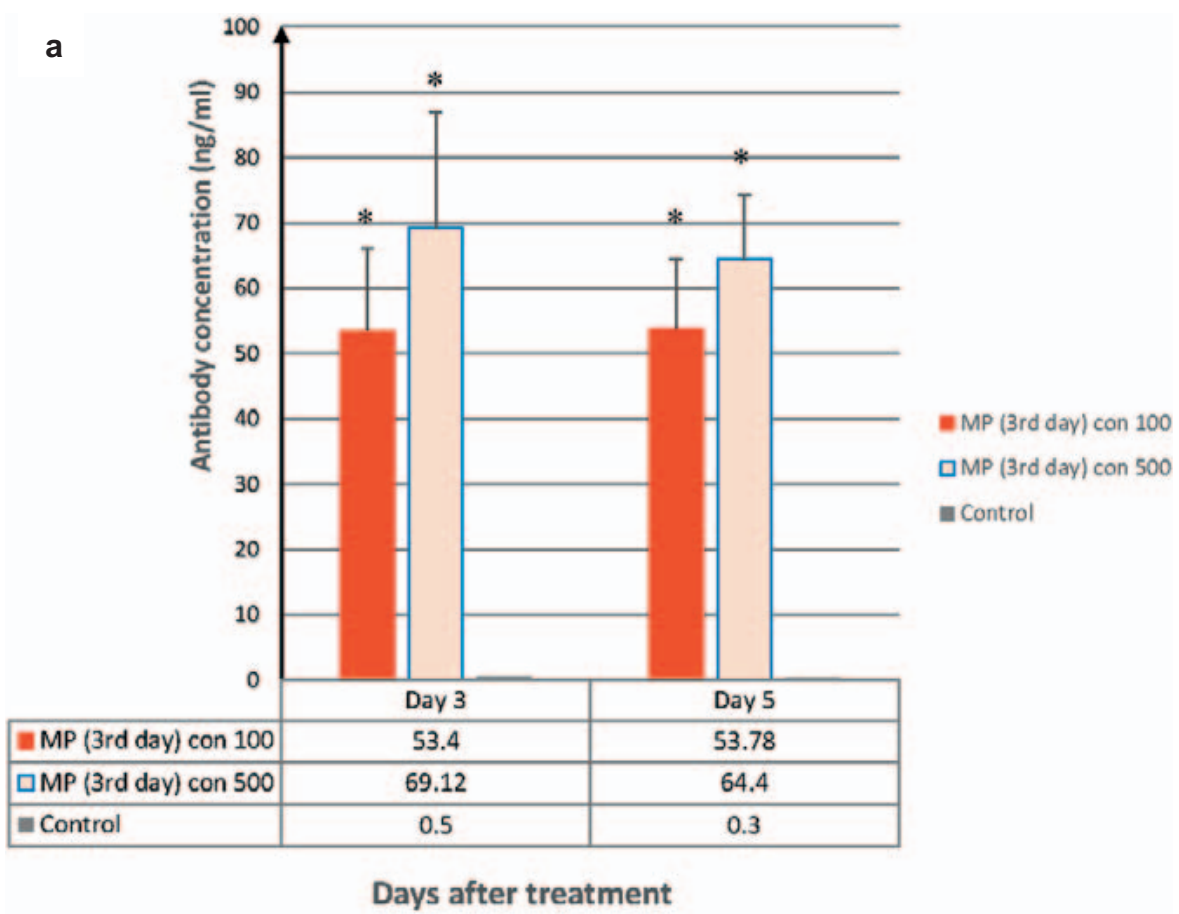

Fig. 5. Results of ELISA method for IgG measurement in the culture media of Daudi cells. Plt-MPs were isolated from platelet concentrate at the 3rd (a) and 7th (b) days of storage and treated with Daudi cells at two different concentrations. The production of IgG was induced in Daudi cells by MPs. Data were presented as the mean \pm SD of five independent experiments. ${ }^{*}$ Indicates the significant difference between the test and control $(\mathrm{p}<0.05)$.

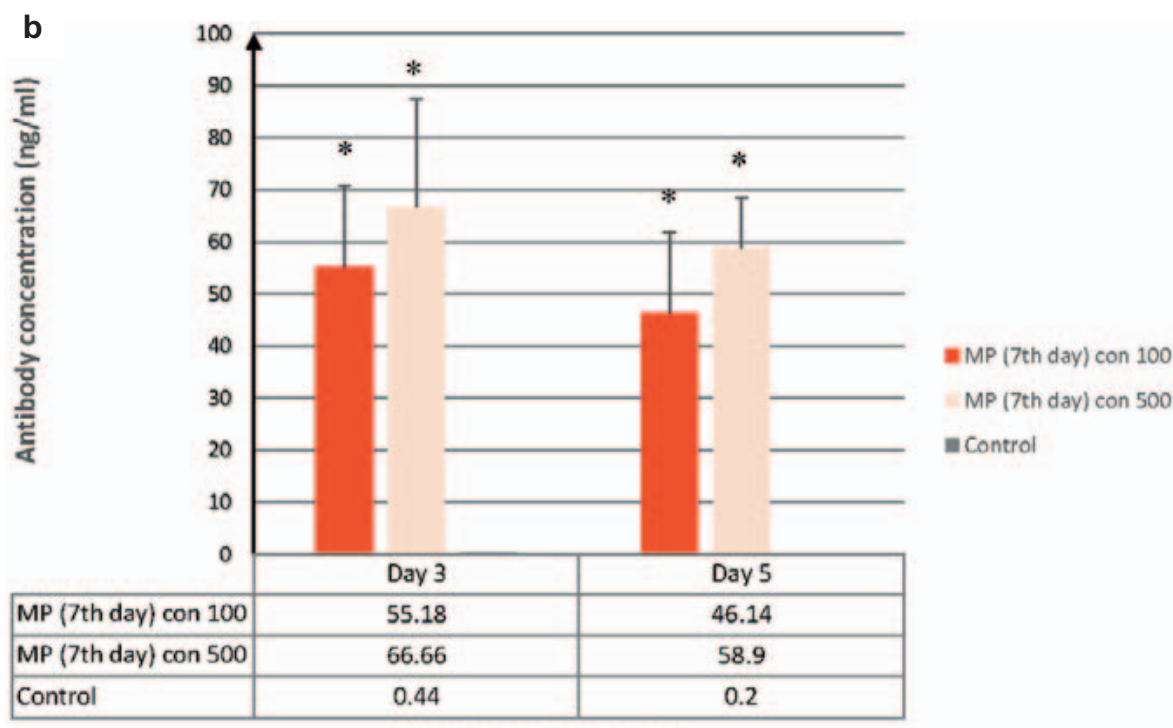

Days after treatment

Immunoglobulin Production from Daudi Cells

The amounts of IgG was measured during the co-culture of Daudi cells and Plt-MPs using ELISA. It became clear that the levels of IgG production by Daudi cells were significantly increased during 5-day co-culture with MPs. The results were shown for the IgG expression by Daudi cells after treatment with Plt-MPs. The comparison was done between the test and control and showed significant differences (fig. 5).

\section{Discussion}

The immunological role of platelets has been recognized [21, 22]. In this study, we investigated the effect of MPs derived from platelets on immunological responses. Using a human B-lymphoblast cell line, i.e. Daudi, the effects of 5-day co-culturing with PltMPs were investigated regarding Ig production and the expression of CD27, CD86 and IgD, reflecting the activation status of these cells. The expression of the selected cell surface markers were correlated with the mutated variable regions as a result of the somatic hypermutation process or the activation of B cells for Ig secretion $[23,24]$.

The present study revealed that following treatment with PltMPs, the production of IgG was increased in Daudi cells. Besides, the expression of cell surface antigens such as CD27 and CD86 was increased, whereas the IgD level was decreased. We could show that the effect of Plt-MPs on these cells was dependent on the concentration of Plt-MPs and the time of their isolation from PCs. 
Working with cell lines is easy, and there is consistency of results from experiment to experiment. The Daudi line is created by EBV infection and is positive for the presence of EBV viral DNA sequences. The cells have normal karyotype and surface immunoglobulin (sIg+). The major difference between primary B lymphocytes and the Daudi cells is the absence of HLA class I on the surface of these cells. In this cell line, translation of the HLA class I $\alpha$-chains is intact, but due to lack of $\beta 2$-microglobulin, HLA class I chains are retained in the cytoplasm of the cells [25].

To our knowledge, this is the first study dealing with the effects of Plt-MPs on an immortalized B-cell line serving as surrogate cells for peripheral blood B cells. Plt-MPs obviously had the ability to induce the production of IgG in Daudi cells. As yet, only few studies had been carried out about the effects of platelets or Plt-MPs on the antibody production of peripheral blood B cells. Cognasse and colleagues [1] showed that the 3-day incubation of platelets with $B$ cells caused B cells to increase the production of IgG and IgM antibodies. .They also reported a decrease in the cell surface expression of IgD on B cells and an increase in the CD27 expression on peripheral blood $\mathrm{B}$ cells after treatment with platelets. The results of Cognasse et al. [1] and our findings presented here showed great similarity with regard to the expression profile of B-cell activation markers, except that we used Plt-MPs instead of platelets. So it could be deduced that Plt-MPs, similar to platelets, have the capability to activate B cells or immortalized cells with B-cell origin.

Sprague and co-workers [3] showed that membranous vesicles derived from platelets caused the production of antibodies and the formation of germinal centers in mice via signals mediated by CD40L. Even though they did not compare different concentra- tions of MPs, they supposed that the antibody production of B cells might be affected by MPs in a dose-dependent manner as shown in the present study.

In previous studies of our working group, we demonstrated that during 5-day co-culture of B lymphocytes with Plt-MPs the production of IgG [20] and the expression of activation markers was stimulated [26]. In the present study, we examined the ability of Plt-MPs to induce Ig production in a human B-cell line (Daudi cells). When co-culturing Daudi cells with $500 \mu \mathrm{g} / \mathrm{ml}$ Plt-MPs, Ig expression was significantly increased and even concentrations of $100 \mu \mathrm{g} / \mathrm{ml}$ Plt-MPs were effective in increasing antibody production in stimulated Daudi cells. The present study thus provides one further clue that adaptive immunity is partially mediated through the membrane vesicles derived from platelets [3]. In response to Plt-MPs, Daudi cells acquire the ability to become activated and create antibodies. Thus it is conceivable that Plt-MPs may play a significant role as immortalized cell activators in human monoclonal antibody technology in near future.

\section{Acknowledgments}

This article is the result of a thesis in Blood Transfusion Research Center, High Institute for Research and Education in Transfusion Medicine. We wish to thank the Institute for the financial and moral support.

\section{Disclosure Statement}

None of the authors has any conflicts of interest to declare.

\section{References}

1 Cognasse F, Hamzeh-Cognasse H, Lafarge S, Chavarin P, Cogné M, Richard Y, Garraud O: Human platelets can activate peripheral blood B cells and increase production of immunoglobulins. Exp Hematol 2007;35: 1376-1387.

2 Danese S, Katz JA, Saibeni S, Papa A, Gasbarrini A, Vecchi M, Fiocchi C: Activated platelets are the source of elevated levels of soluble CD40 ligand in the circulation of inflammatory bowel disease patients. Gut 2003; 52:1435-1441.

3 Sprague DL, Elzey BD, Crist SA, Waldschmidt TJ Jensen RJ, Ratliff TL: Platelet mediated modulation of adaptive immunity: unique delivery of CD154 signal by platelet-derived membrane vesicles. Blood 2008; 111:5028-5036.

4 Mause SF, Weber C: Microparticles: protagonists of a novel communication network for intercellular information exchange. Circ Res 2010;107:1047-1057.

5 Italiano JE Jr, Mairuhu AT, Flaumenhaft R: Clinical relevance of microparticles from platelets and megakaryocytes. Curr Opin Hematol 2010;17:578-584.

6 Tissot JD, Canellini G, Rubin O, Angelillo-Scherrer A, Delobel J, Prudent M, Lion N: Blood microvesicles: from proteomics to physiology. Transl Proteom 2013; 1:38-52.

7 Burnier L, Fontana P, Kwak B, Scherrer A: Cellderived microparticles in haemostasis and vascular medicine. Thromb Haemost 2009;101:439-451.
8 van der Meel R, Krawczyk-Durka M, van Solinge WW, Schiffelers RM: Toward routine detection of extracellular vesicles in clinical samples. Int J Lab Hematol 2014;36:244-253.

9 Mayne E, Funderburg NT, Sieg SF, Asaad R, Kalinowska M, Rodriguez B, Schmaier AH, Stevens W, Lederman MM: Increased platelet and microparticle activation in HIV infection: upregulation of P-selectin and tissue factor expression. J Acquir Immune Defic Syndr 2012;59:340-346

10 Khan SY, Kelher MR, Heal JM, Blumberg N, Boshkov LK, Phipps R, Gettings KF, McLaughlin NJ, Silliman CC: Soluble CD40 ligand accumulates in stored blood components, primes neutrophils through CD40, and is a potential cofactor in the development of transfusionrelated acute lung injury. Blood 2006;108:2455-2462.

11 Leroyer AS, Rautou PE, Silvestre JS, Castier Y, Lesèche G, Devue C, Duriez M, Brandes RP, Lutgens E, Tedgui A, Boulanger CM: CD40 ligand+ microparticles from human atherosclerotic plaques stimulate endothelialproliferation and angiogenesis a potential mechanism for intraplaque neovascularization. J Am Coll Cardiol 2008;52:1302-1311.

12 Nomura S, Ozaki Y, Ikeda Y: Function and role of microparticles in various clinical settings. Thromb Res 2008;23:8-23.
13 Valadi H, Ekström K, Bossios A, Sjöstrand M, Lee JJ, Lötvall JO: Exosome-mediated transfer of mRNAs and microRNAs is a novel mechanism of genetic exchange between cells. Nat Cell Biol 2007;9:654-659.

14 Janowska-Wieczorek A, Majka M, Kijowski J, BajKrzyworzeka M, Reca R, Turner AR, Ratajczak J, Emerson SG, Kowalska MA, Ratajczak MZ: Plateletderived microparticles bind to hematopoietic stem/ progenitor cells and enhance their engraftment. Blood 2001;98:3143-3149.

15 Barry OP, Pratico D, Lawson JA, FitzGerald GA: Transcellular activation of platelets and endothelial cells by bioactive lipids in platelet microparticles. J Clin Invest. 1997;99:2118-2127.

16 Rozmyslowicz T, Majka M, Kijowski J, Murphy SL, Conover DO, Poncz M, Ratajczak J, Gaulton GN, Ratajczak MZ: Platelet- and megakaryocyte-derived microparticles transfer CXCR4 receptor to CXCR4null cells and make them susceptible to infection by X4-HIV. AIDS 2003;17:33-42.

17 Jahromi M, Yari F, Esmaeili MA: Effect of plateletderived microparticles on the production of IgG antibody from human peripheral blood B-Lymphocytes. J Mazandaran University Med Sc 2016;25:267-276.

18 Roback JD, Grossman BJ, Harris T, Hillyer CD (Ed.): Technical Manual \& Methods, 17th ed. Bethesda, American Association of Blood Banks,2011, pp 199219. 
19 Deyhim MR, Mesbah-Namin SA, Yari F, Taghikhani $\mathrm{M}$, Amirizadeh N: L-carnitine effectively improves the metabolism and quality of platelet concentrates during storage. Ann Hematol 2015;94:671-680.

20 Yari F, Ahmadzadeh N, Azadpour S, Vaeli S: HLA antigens shed from the surface of synthetic or naturally occurred platelet-derived microparticles during storage of platelet concentrate. Indian J Hematol Blood Transfus 2012;28:152-156.

21 Tamagawa-Mineoka R: Important roles of platelets as immune cells in the skin. J Dermatol Sci 2015;77:93101.
22 Morrell CN, Aggrey AA, Chapman LM, Modjeski KL: Emerging roles for platelets as immune and inflammatory cells. Blood 2014;123:2759-2767.

23 Klein U, Rajewsky K, Küppers R: Human Ig (Ig) $\mathrm{M}+\mathrm{IgD}+$ peripheral blood $\mathrm{B}$ cells expressing the $\mathrm{CD} 27$ cell surface antigen carry somatically mutated variable region genes: CD27 as a general marker for somatically mutated (memory) B cells. J Exp Med 1998;188:16791689.
24 Rau FC, Dieter J, Luo Z, Priest SO, Baumgarth N: B71/2 (CD80/CD86) direct signaling to B cells enhances IgG secretion. J Immunol 2009;183:7661-7671.

25 Rosa F, Fellous M, Dron M, Tovey M, Revel M: Presence of an abnormal beta 2-microglobulin mRNA in Daudi cells: induction by interferon. Immunogenetics 1983;17:125-131.

26 Esmaili MA, Yari F, Sharifi Z, Nikougoftar M, Fadaei R: Effects of platelet microparticles on the activation of B Cells. Modares J Med Sci Pathobiol 2013;15:1-10. 